\title{
Barium Compounds through Monte Carlo Simulations Compare the Performance of Medical Radiation Shielding Analysis
}

\author{
Seonchil Kim*, Kyotae Kim*, Jikoon Park** \\ Dept of Radiological Technology, Daegu Health college*, Dept. of Hybrid Medicine and Science, Inje University ${ }^{* *}$ \\ Dept. of Radiological Science, International University of Korea ${ }^{* * *}$
}

\section{몬테카를로 시뮬레이션을 통한 바륨화합물의 의료방사선 차폐능 비교 분석}

\author{
김선칠*, 김교태**, 박지군*** \\ 대구보건대학교 방사선과*, 인제대학교 융합의과학**, 한국국제대학교 방사선학과***
}

\begin{abstract}
This study made a tentative estimation of the shielding rate of barium compound by thickness through monte carlo simulation to apply medical radiation shielding products that can replace existing lead. Barium sulfate $\left(\mathrm{BaSO}_{4}\right)$ was used for the shielding material, and thickness of the shielding material specimen was simulated from $0.1 \mathrm{~mm}$ to $5 \mathrm{~mm}$ by applying $15 \times 15 \mathrm{~cm}^{2}$ of specimen area, $4.5 \mathrm{~g} / \mathrm{cm}^{3}$ of density of barium sulfate, and $11.34 \mathrm{~g} / \mathrm{cm}^{3}$ density of lead. Entered source was simulated with $10 \mathrm{kVp}$ Step in consecutive X-ray energy $\operatorname{spectrum}(40 \mathrm{kVp} \sim 120 \mathrm{kVp})$. Absorption probability in $40 \mathrm{kVp} \sim 60 \mathrm{kVp}$ showed same shielding rate with lead in $3 \mathrm{~mm} \sim 5 \mathrm{~mm}$ of thickness, but it was identified that under $2 \mathrm{~mm}$, the shielding rate was a bit lower than the existing lead shielding material. Also, the shielding rate in $70 \mathrm{kVp} \sim 120 \mathrm{kVp}$ energy band showed similar performance as the existing lead shielding material, but it was tentatively estimated as fairly low shielding rate below $0.5 \mathrm{~mm}$. This study estimated the shielding rate of barium compound as the thickness function of $\mathrm{x}$-ray energy band for medical radiation through monte carlo simulation, and made comparative analysis with existing lead. Also, this study intended to verify application validity of the $\mathrm{x}$-ray shielding material for medical radiation of pure barium sulfate. As a result, it was estimated that the shielding effect was $95 \%$ higher than the existing lead $1.5 \mathrm{~mm}$ in at least $2 \mathrm{~mm}$ thickness of barium compound in medical radiation energy band 70 $\mathrm{kVp} \sim 120 \mathrm{kVp}$, and this result is considered valid to be provided as a base data in weight lightening production of radiation shielding product for medical radiation.
\end{abstract}

Key Words: Monte Carlo Simulation, Lead, Barium sulfate, Shielding rate

\section{요 약}

본 연구에서는 기존의 납을 대체할 수 있는 의료 방사선 차폐제품 적용을 위해 몬테카를로 시뮬레이션을 통해 바륨 화합물의 두께별 차폐능을 모의 추정하였다. 차폐재 물질로는 황산바륨 $\left(\mathrm{BaSO}_{4}\right)$ 을 이용하였고, 시편의 면적은 $15 \times$ 


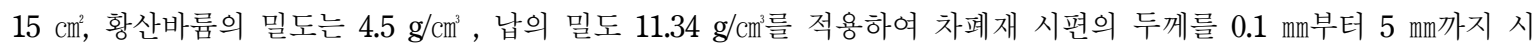
뮬레이션 하였다. 입력 선원은 연속 X-ray 에너지 스펙트럼 $40 \mathrm{kVp} \sim 120 \mathrm{kVp}$ )에서 $10 \mathrm{kVp}$ Step으로 시뮬레이션 하였다. $40 \mathrm{kVp} \sim 60 \mathrm{kVp}$ 에서의 흡수확률은 $3 \mathrm{~mm} \sim 5 \mathrm{~mm}$ 두께에서는 납과 동일한 차폐능을 나타내었으나, $2 \mathrm{~mm}$ 이 하에서는 차폐능이 기존 납 차폐재에 비해 다소 차폐능이 떨어지는 결과로 나타났다. 또한 $70 \mathrm{kVp} \sim 120 \mathrm{kVp}$ 에너지 대역에서의 차폐능은 기존 납 차폐재와 유사한 성능을 보였지만, $0.5 \mathrm{~mm}$ 이하에서는 다소 낮은 차폐능으로 모의 추정 되었다. 본 연구는 몬테카를로 시률레이션을 통해 의료용 엑스선 에너지 대역에 대한 두께 함수로써 바륨화합물의 차 폐능을 추정하여 기존의 납과 비교 분석하였다. 또한 순수한 황산바륨의 의료용 방사선 차폐제품 적용가능성을 검증하 고자 하였다. 그 결과 의료 방사선 에너지 대역 $70 \mathrm{kVp} \sim 120 \mathrm{kVp}$ 에서 최소 $2 \mathrm{~mm}$ 이상의 바륨화합물 두께에서 기존 납 $1.5 \mathrm{~mm}$ 대비 $95 \%$ 이상의 차폐효과가 있는 것으로 추정되었으며, 본 결과는 의료용 방사선 차폐제품의 경량화 제작 에 기초 자료로 제공될 수 있을 것으로 사료된다.

중심단어: 몬테카를로 시뮬레이션, 납, 황산바륨, 차폐능

\section{I. 서 론}

방사선을 이용한 의료 분야의 검사과정에서 불필요 한 방사선을 차폐하고자 하는 노력은 매우 중요하다. 현재 의료기관에서 차폐물질로 가장 많이 사용되는 것은 납으로, 얇은 시트 형태로 만들어질 만큼 가공성 이 좋지만, 최근 중금속이라는 점 때문에 의료 환경에 서 외면을 받고 있으며 대체 물질에 대한 연구도 지속 되고 있다 ${ }^{[1]}$.

대표적인 차폐 대체 물질은 텅스텐, 붕소, 바륨, 비 스무트, 티타늄 등이 있달]-[5]. 그러나 납과 같은 가공 성과 경제성을 유지하면서 의료방사선 방어 환경을 개선할 수 있는 물질을 찾는 것은 쉬운 일이 아니다. 특히 제품화가 될 때까지 가장 중요한 것은 경제성이 다. 이에 본 연구에서는 기존에 투시조영 검사를 통해 안정성이 입증된 황산바륨 즉, 바륨 화합물을 기존의 납의 대체물질로의 적용 가능성을 연구하고자 하였다. 황산바륨은 납 만큼 우수한 가공성과 경제성을 지니 고 있으며, 관련 연구 분야에서도 가장 많이 사용되고 있는 차폐 대체 물질로 제시되고 있다 ${ }^{[6],[7]}$. 기존 선행 연구에서는 MCNPX(Monte Carlo N-Particle Extended) 시뮬레이션을 통해 납 대체 여러 물질의 에너지대 영 역에 대한 차폐능을 단순 비교한 것으로 제품화에 필 요한 적당한 두께 설정과 경량화에 한계가 있어서 대 상 물질의 혼합과 교반 등과 같은 공정에 이용하는데 다소 부족하였다 ${ }^{[7]-[9]}$.

따라서 본 연구에서는 실제 바륨화합물의 제조 공 정에 들어가기 전, 몬테카를로 시뮬레이션을 이용하여
바륨화합물을 일정 크기의 두께별로 나누어 의료방사 선 에너지 영역에서의 두께별 흡수스펙트럼 분석을 통하여 차폐능을 알아보고, 이를 납과 비교하여 순수 한 바륨 화합물의 차폐 효과를 입증하고자 한다. 또한 일정 에너지대 영역에서 적절한 두께를 선정하고, 이 를 근거로 납을 대체할 수 있는 의료용 방사선 차폐재 로써 가능성과 경량화 근거 제시 및 의료검사환경에 서의 적절성을 동시에 고찰하고자 한다.

\section{II. 실험 및 방법}

의료분야에서 일반 방사선 촬영과 동일한 조건으로 모의추정하기 위한 방법으로 $\mathrm{MCNP}(\operatorname{Los} \mathrm{Alamos}$ National Laboratory, USA, Ver. X) 코딩을 이용하였다 ${ }^{[7]}$. 차폐재 물질로는 황산바륨 $\left(\mathrm{BaSO}_{4}\right)$ 을 이용하였는데 화합물 내 구성물질의 원자번호는 바륨 56번, 황 16 번, 산소 8 번으로 코딩하였고, 시편의 면적은 $15 \times 15 \mathrm{~cm}^{2}$, 시편의 두께는 $0.1 \mathrm{~mm}$ 부터 $0.5 \mathrm{~mm}$ 까지 입력을 하였고, 황산바륨의 밀도는 $4.5 \mathrm{~g} / \mathrm{cm}^{3}$, 납의 밀도는 $11.34 \mathrm{~g} / \mathrm{cm}^{3}$ 으로 기준을 정하였다.

진단 영역의 X선 광자들에 대해 물질과의 상호 작 용하여 통과한 광자들의 에너지 스펙트럼을 추적하기 위해 Mode P를 이용하여 X선 광자들의 전달을 정의 하였다. Cell \& Surface Card에서는 광자에 대한 중요성 을 '1'로 하였고, 시편 외부 빈 공간에서는 광자를 막기 위해 중요성을 ' 0 '으로 하였다. 


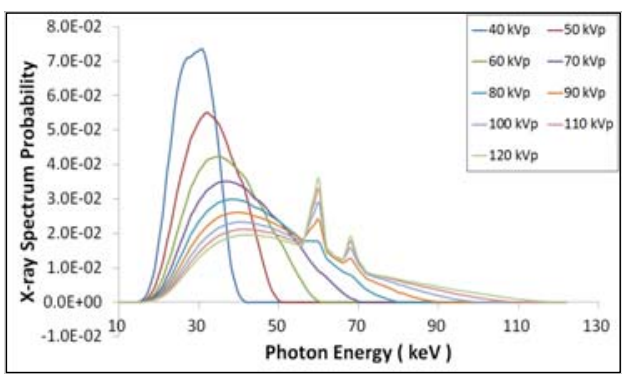

Fig. 1. X-ray Spectrum of Simulation.

시뮬레이션 시 이용선원은 $40 \mathrm{kVp} \sim 120 \mathrm{kVp}$ 대역 의 연속 X-ray 에너지 스펙트럼을 $10 \mathrm{kVp}$ 간격으로 적 용하였으며, 이 때 사용한 에너지 스펙트럼은 X선관의 관전압 맥동률 $13.4 \%$, 사용필터 $2.1 \mathrm{mmAl}$ 에 대하여 텅 스텐 저지체에서 발생하는 스펙트럼을 이용하였다. 그 림 1은 몬테카를로 시뮬레이션에 이용하기 위하여 이 용한 텅스텐 저지체 존재비 스펙트럼 분포를 나타내 고 있다. ERG는 연속 $\mathrm{X}$ 선 광자의 에너지 분포 데이터 를 선원 정보(SI), 선원 확률(SP)를 이용하여 선원 에너 지의 히스토그램을 정의했다. 선원 입자의 샘플링은 SUR을 이용하여 납과 바륨 직육면체 시편의 표면에서 $\mathrm{X}$ 선 광자들을 발생하고 선원 입자 타입을 정의하는 PAR는 광자에 해당하는 PAR2를 이용하였다. Tally Specification cards는 F1 Tally를 이용하여 X선의 한 표 면에 입사하는 광자가 반대쪽 표면을 통과할 확률을 50,000 번 이벤트로 모의 추정하였다.

\section{III. 결 과}

납을 대체할 수 있는 친환경 차폐시트를 제작하기 위해서는 재료로 사용되는 바륨화합물의 기본적인 차 폐능 분석이 필요하다. 이를 몬테카를로 시뮬레이션을 통한 모의 추정결과를 적용하여 임상에서 현재 사용 하고 있는 납 시트와 바륨화합물 시트의 차폐능 결과 는 아래와 같이 도출되었다.

\section{X선 에너지대 별 차폐능 분석}

의료방사선의 진단용 영역은 $40 \mathrm{kVp} \sim 150 \mathrm{kVp}$ 에 서 주로 사용되고 있으며, 납의 흡수단 영역은 주로 $15 \mathrm{keV}$ (L-Edge)와 $88 \mathrm{keV}(\mathrm{K}$-Edge)로 알려져 있으며,

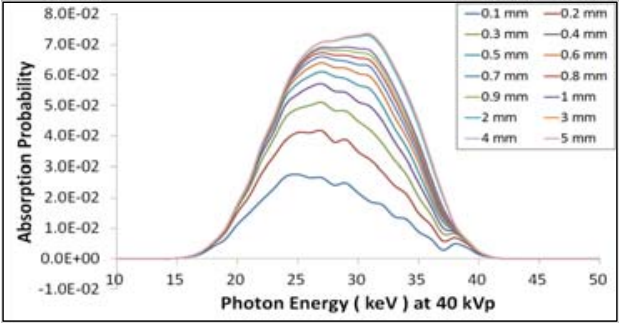

(a)

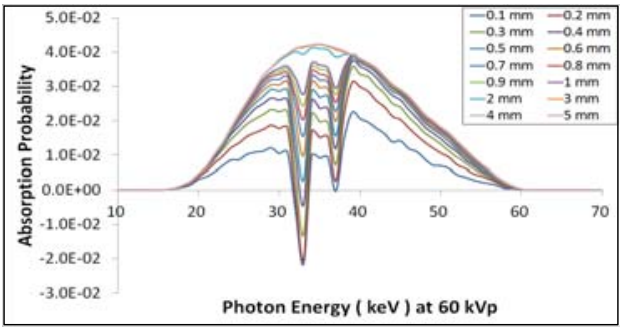

(b)

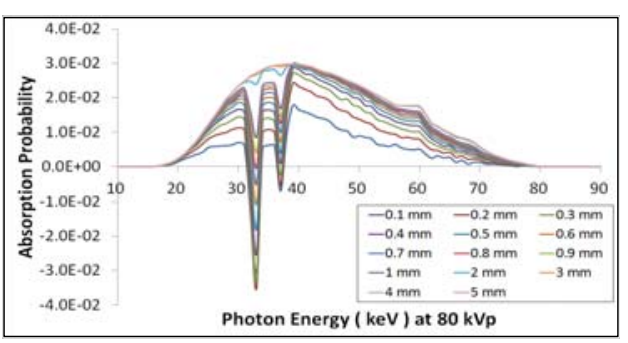

(c)

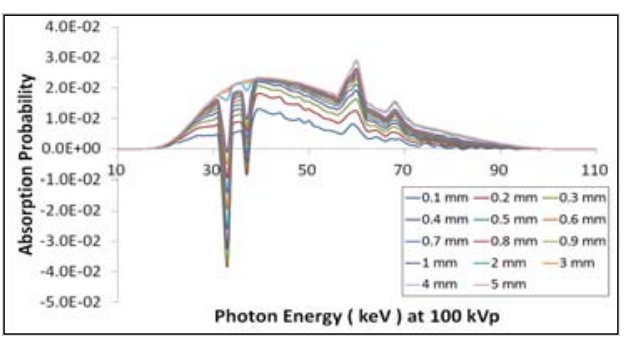

(d)

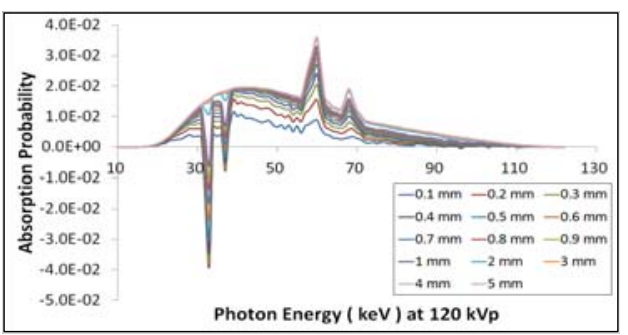

(e) 


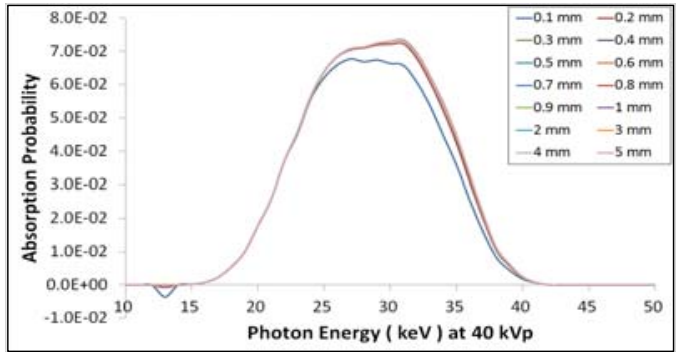

(f)

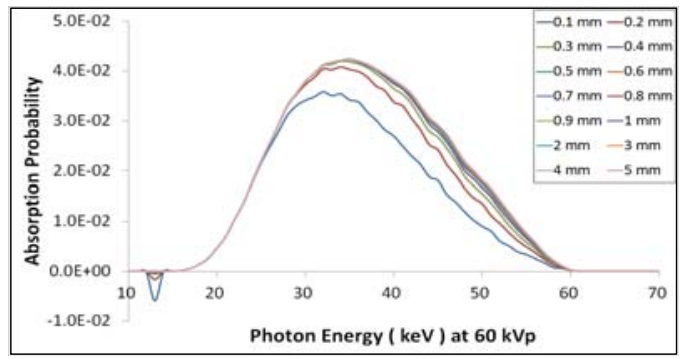

(g)

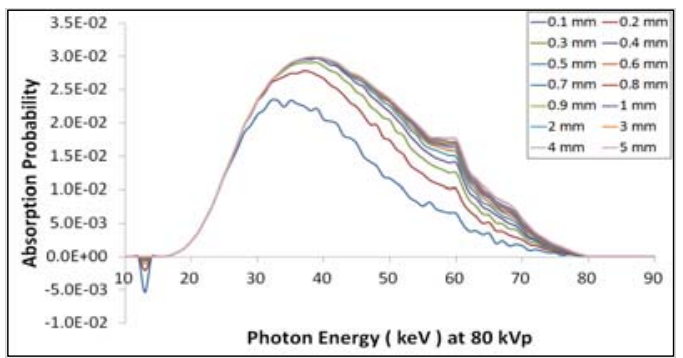

(h)

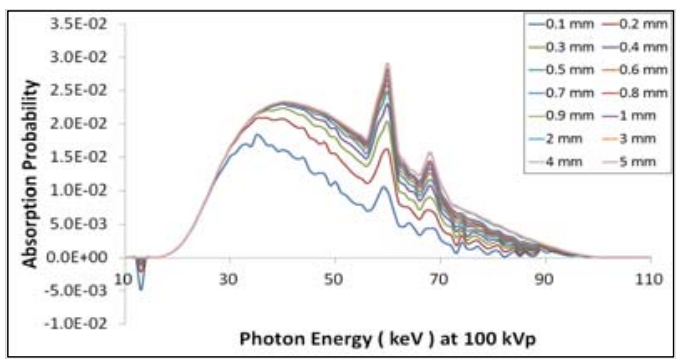

(i)

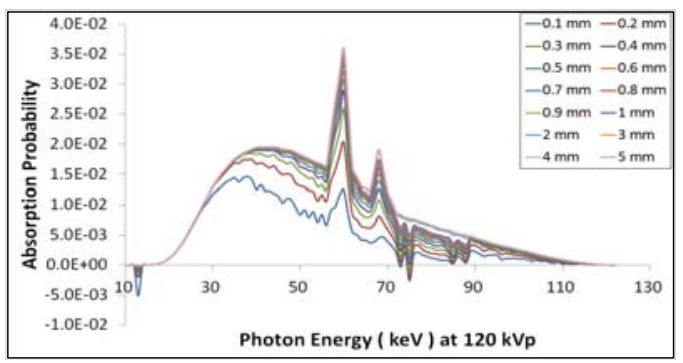

(g)

Fig. 2. Absorption probability as a function of photon enery (a $\sim$ e) Barium compound and ( $\sim$ g) Lead.
바륨은 $5 \mathrm{keV}(\mathrm{L}-\mathrm{Edge})$ 와 $37 \mathrm{keV}$ (K-Edge)의 흡수단을 가지는 것으로 알려져 있다 ${ }^{[8]}$. 본 연구에서는 동일한 에너지대 영역에서 납과 황산바륨의 차폐능을 비교하 여 에너지 영역별로 분석하였다. 낮은 에너지대 영역 을 중심으로 일부 영역에서 납과 동일한 차폐능을 보 일 것으로 예상했던 황산바륨의 모의 추정 결과, 그림 2 와 같이 $4 \mathrm{~mm} \sim 5 \mathrm{~mm}$ 두께의 시트에서는 납에 근접 한 흡수능을 보였다. 기존의 차폐 영역에서 많이 제외 되었던 낮은 영역의 에너지에서 황산바륨은 다소 낮 은 흡수능을 나타내었다.

\section{2. 바륨 화합물 두께별 차폐능 비교 분석}

Apron과 같은 차폐복을 제작하기 위해서 기존의 해 결해야 할 문제인 경량화를 시뮬레이션 통해 두께를 모의 추정을 하여 비교 분석하였다. 모의 추정 결과를 분석하여 두께에 따른 차폐능을 Fig. 3에 나타내었고, Fig. 4는 이를 비교하였다.

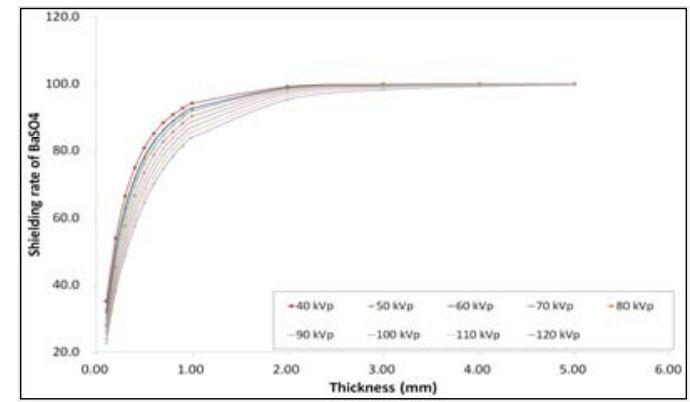

(a)

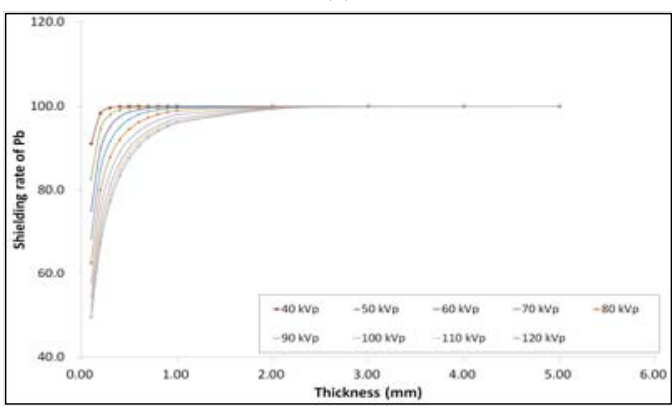

(b)

Fig. 3. shielding rate as a function of material thickness (a) Barium compound and (b) Lead.

Fig. 3에서 차폐 형태를 분석해 보면 기존의 납의 경 우, $0.4 \mathrm{~mm}$ 부터 $80 \%$ 이상을 유지하였고, 황산바륨의 경 우 $0.9 \mathrm{~mm}$ 에서 유지하는 것으로 모의추정 되었다. 


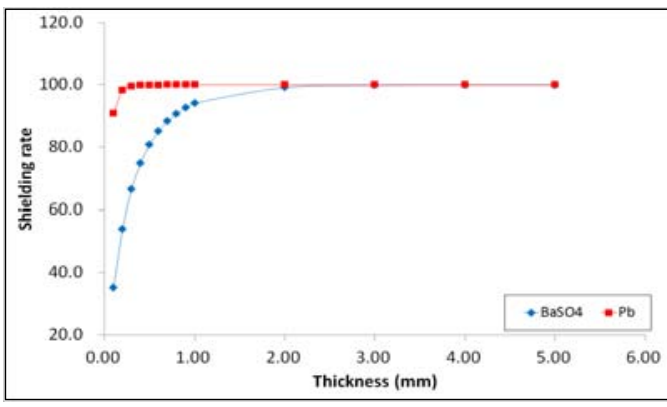

(a)

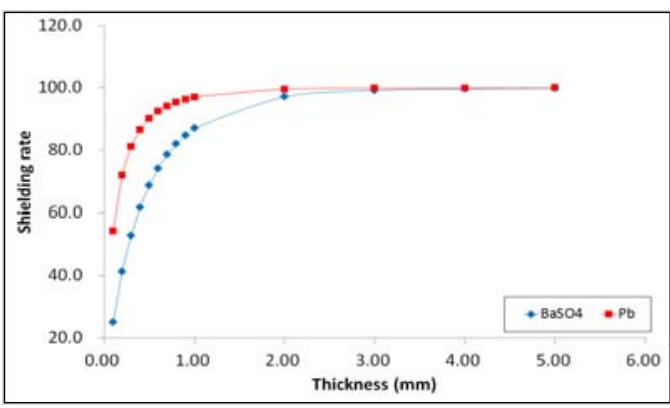

(b)

Fig. 4. shielding rate as a function of material thickness (a) $40 \mathrm{kVp}$ and (b) $100 \mathrm{keV}$.

Fig. 4에서는 에너지대 영역에서 두께별 차폐능은 유사한 형태로 나타나는 것을 알 수 있고, 납 $1.5 \mathrm{~mm}$, 황산바륨의 경우 $2 \mathrm{~mm}$ 부터 전반적인 차폐가 완벽하게 이루어졌다. 이러한 결과를 이용하여 무게를 산출하고 비교 시, 납 같은 경우 $1.5 \mathrm{~mm}$ 로 산출할 경우 $0.38 \mathrm{~kg}$ 으 로 산출되었고, 황산바륨의 경우 $2 \mathrm{~mm}$ 일 경우 $0.20 \mathrm{~kg}$ 으로 산출되었다. 이러한 결과는 바륨을 이용 시 납 보다 경량화된 에이프런의 제작 가능성을 가지는 것 으로 사료된다.

\section{IV. 고 찰}

몬테카를로 시뮬레이션은 구하고자 하는 수치의 확 률적 분포를 반복 가능한 실험 통계로 나타내는 방법 을 말한다. 현재 납을 제외한 차폐시트의 대량생산의 한계점은 차폐 재료와 참가물의 교반을 통해 제작하 여 동일한 차폐능을 얻는 것인데 일정량 이상의 대용 량인 경우는 교반 등의 혼합과정 한계로 동일한 차폐 성능을 유지하기 힘들다. 이와 같은 문제점으로 인해 제작 비용이 많이 들어 제품의 경제성이 떨어진다.

따라서 본 연구에서 제시된 에너지대 영역별 시트
두께를 미리 계산하여 제작한 뒤 직접선, 산란선 차폐 등 다양한 목적으로 차폐복을 생산하기 위한 두께별 차폐능을 모의 추정 하였다. 의료방사선 사용영역 중 진단 영역에서 사용되는 방사선 차폐는 대체로 0.25 $\mathrm{mmPb} \sim 1.0 \mathrm{mmPb}$ 이 사용되고, 이 중 $0.5 \mathrm{mmPb}$ 는 가장 많이 사용하는 기존 제품인 에이프런으로 약 $4.95 \mathrm{~kg}$ 의 무게를 가지며, 차폐능은 $50 \mathrm{kVp}$ 에서 $99.9 \%, 75$ $\mathrm{kVp}$ 에서는 $88 \%, 100 \mathrm{kVp}$ 에서는 $75 \%$ 정도 차폐 되는 것으로 알려져 있다 ${ }^{[9]}$. 본 연구 결과, 납은 $1.5 \mathrm{~mm}$ 에서 $100 \%$ 차폐 되는 것으로 나타났고, $0.4 \mathrm{~mm}$ 에서 $80 \%$ 이 상 차폐되는 것으로 나타났다. 이에 비해 황산바륨은 $2.0 \mathrm{~mm}$ 에서 $100 \%$ 차폐되는 것으로 나타났고, $0.9 \mathrm{~mm}$ 에 서 $80 \%$ 이상 차폐되는 것으로 나타났다. 또한 무게를 산출한 결과 $100 \%$ 차폐의 경우 납은 $0.38 \mathrm{~kg}$, 황산바륨 은 $0.20 \mathrm{~kg}$ 으로 산출되었고, $80 \%$ 차폐의 경우 납은 0.1 $\mathrm{kg}$, 바륨은 $0.09 \mathrm{~kg}$ 으로 납 보다 황산바륨을 이용하여 Apron 제작 시에 경제적이면서, 경량화를 이룰 수 있 을 것으로 사료된다.하지만, 황산바륨은 $40 \mathrm{keV}$ 이하 의 저에너지에서는 납과 비교하였을 경우 매우 불안 전하고 변화가 큰 차폐능을 보인다. 이는 의료방사선 영역에서는 저에너지 영역을 잘 이용한다면 차폐효과 를 극대화 할 수 있을 것으로 사료된다.

에너지대 영역별 차폐능이 두께로 표현될 수 있기 때문에 바륨화합물을 이용한 얇은 섬유나 패드 등으 로 충분히 차폐가 가능한 저감섬유를 제작하여 저선 량 방사선을 차폐 할 수 있다. 본 연구결과 황산바륨 이 최소 $3 \mathrm{~mm} \sim 5 \mathrm{~mm}$ 에서 납과 유사한 차폐능을 보이 고 있는데 이는 향후 제작공정에서 두께를 최소화는 방법을 찾아야 할 것으로 사료된다. 또한 실리콘과 같 은 혼합 재질에서는 바륨화합물의 기포 제거률과 공 극률을 높이는데 중점을 두어야 하고 이는 차폐능과 직접적인 관계를 가지고 있다 ${ }^{[10]}$.

\section{$\mathrm{V}$. 결 론}

본 연구는 바륨 화합물의 차폐능을 평가하고자 기 존 에이프런에서 사용하고 있는 납을 기준으로 비교 하였다. 의료방사선 영역 중에서 대체로 두께가 두꺼 운 $3 \mathrm{~mm} \sim 5 \mathrm{~mm}$ 영역에서 납과 동일한 차폐성능을 보 이고 있어 에이프런과 같은 직접선 차폐로 사용되는 
데 무리가 없을 것으로 모의추정 되었으며, 흡수확률 및 두께별 차폐성능 을 검토해 보면 최소 $2 \mathrm{~mm} \sim 5 \mathrm{~mm}$ 대의 황산바륨의 차폐능이 효과적으로 추정되었다. 따 라서 황산바륨을 이용한 화합물 제작 시 최소 $2 \mathrm{~mm}$ 에 서 시작되므로 관련 화합물을 첨가 혼합하는 과정에 서 두께를 줄이는 과정과 경량화하는 과정의 기준점 으로 이용 가능할 것으로 사료된다.

\section{참고문헌}

[1] Kyotae Kim, etc "Absorbed spectrum comparison of lead and tungsten in continuous x-ray energy using monte carlo simulation" J. Korean. soc. radiol, Vol. 27, pp 483-487, 2012.

[2] Korean intellectual property office patent gazette (A), Radiation shielding fabric, Number 10-2009-0011082, 2009.

[3] Korean intellectual property office patent gazette (A), Radiation shielding fabric, Number 10-08600332, 2008.

[4] Korean intellectual property office patent gazette (A), Excellent X-ray shielding textile products and its manufacturing method, Number 2001-0056190, 2001.

[5] Korean intellectual property office patent gazette (A), Barium sulfate fiber and manufacturing method of radiation shielding, Number 2000-0007084, 2000.

[6] Kim, Y.K., Jang, Y.I., Kim, J.M., The weight of the apron for radiation protection and shielding performance improvement, Journal of Radiol. Sci. Tech., Vol. 26, pp. 45-51, 2003.

[7] Kim, S.C. Park, M.H., Development of radiation shield with environmentally-friendly materials; I : Comparison and evaluation of fiber, rubber, silicon in the radiation shielding sheet. Journal Radiol Sci. Technol., Vol. 33, pp. 121-126, 2010.

[8] Judith.F. Briesmeister, "MCNPTM A General Monte Carlo N-Particle Transsport Code. Ver. 4C", 2000.

[9] Akkurt, I., Basyigit, C., Kilincarslan, S., Mavi, B., Akkurt, A., "Radiation shielding of concretes containing different aggregates". Cem. Concr. Compos. Vol. 28, pp. 153-157, 2006.

[10] Bushong SC: Radiologic science for technologists. 2nd ed. The C.V. Mosby Company, ST. Louis, Toronto, London, pp. 98-445, 1980.

[11] Kim, S.C., Park, M.H., Development of radiation shielding sheet with environmentally-friendly materials. II: evaluation of Barum, Tourmaline, silicon polymers in the radiation shielding sheet. J. Radiol. Sci. Technol. Vol. 34, pp. 141-147, 2011. 